\section{Seeing and managing the icebergs}

\author{
Jan C Frich (1) , ${ }^{1}$ Dominique Allwood, ${ }^{2}$ Anthony Robert Berendt, ${ }^{3}$ \\ Pedro Delgado, ${ }^{4}$ Rachel Dunscombe (1), ${ }^{5}$ Bob Klaber, ${ }^{6}$ \\ Aoife Caitlin Molloy 주, 7,8 James Mountford, ${ }^{9,10}$ Amit Nigam (1) ,' \\ Catherine Stoddart (1), ${ }^{12}$ Tim Swanwick 다, ${ }^{13,14}$ Indra Joshi ${ }^{15}$
}

"Structural violence is silent, it does not show-it is essentially static, it is the tranquil waters."- Johan Galtung ${ }^{1}$

The sinking of RMS Titanic on 15 April 1912 has taught us some important lessons about leadership, hubris, safety culture and the importance of accounting for the parts of the iceberg we do not see. Twothirds of the passengers did not survive the tragic incident, and famously, social class and sex were important determinants of passenger's chances of surviving. ${ }^{2}$ There was more than one iceberg at play. What are the icebergs we should be more aware today of when reflecting on leadership challenges and inequalities in the health services and in health?

One challenge that has long hidden in plain sight is the need to better meet the needs of people disadvantaged by race, gender, class or other sources of inequality. In a modern society, interactions with the healthcare system are not optional: people are literally born interacting with it. The system, including hospitals, public health, primary care and community services, is

'Department of Health Management and Health Economics, Institute of Health and Society, University of Oslo, Oslo, Norway

${ }^{2}$ Medical Directors Office, Imperial College Healthcare NHS Trust, London, UK

${ }^{3}$ Department of Continuing Education, University of Oxford, Oxford, UK

${ }^{4}$ Institute for Healthcare Improvement, Boston,

Massachusetts, USA

${ }^{5}$ Institute of Global Health Innovation, Imperial College London, London, UK

${ }^{6}$ Imperial College Healthcare NHS Trust, London, UK

${ }^{7}$ Quality Strategy Team, NHS England, London, UK

${ }^{8}$ The Health Foundation, The Health Foundation,

London, UK

${ }^{9}$ Royal Free London NHS Foundation Trust, London, UK

${ }^{10}$ UCLPartners, London, UK

${ }^{11}$ Cass Business School, London, UK

${ }^{12}$ Health Department, Northern Territory Department

of Health and Families, Casuarina, Australian Capital Territory, Australia

${ }^{13}$ People Directorate, NHS England and NHS

Improvement, Leeds, UK

${ }^{14}$ Faculty of Medical Leadership and Management, London, UK

${ }^{15} \mathrm{NHS}$ England and NHS Improvement London, London, UK

\section{Correspondence to}

Professor Jan C Frich, Department of Health Management and Health Economics, Institute of Health and Society, University of Oslo, 0316 Oslo, Oslo, Norway; jan.frich@medisin.uio.no meant to serve all citizens, without regard to gender, social or ethnic background and race. Nevertheless, social determinants have a huge impact on disease burden and mortality. ${ }^{3}$ How well do our systems address health disparities? How well do they adapt to the population's diversity in needs, preferences, health literacy and service utilisation? How can services better target vulnerable groups and those who experience barriers to access? Further, in every country, health and care systems are major employers: to what extent do systems model and promote equity and inclusion in the workforce?

The COVID-19 pandemic has called for extraordinary and rapid transformations of service delivery, ${ }^{4}$ and creativity and improvisation has played an important role. ${ }^{5}$ Nevertheless, this creativity and improvisation have thus far stopped short of mitigating the effects of societal inequalities. The burden of COVID-19 is distributed unevenly among social groups, both in terms of mortality and the financial effects of societal lockdown. Paul Farmer's observation 20 years ago that in emerging infectious diseases 'social forces and processes come to be embodied as biological events' is no less relevant today. ${ }^{6}$ In part, these social forces may be so enduring and violent, and rooted in such a diverse set of institutions and cultural or social practices that no health system can fully compensate. In part, however, these societal inequalities may also be a blind spot for many health leaders-part of the iceberg that sits below the water. As a result, they may not always have the priority they merit on every leadership agenda, both during the COVID-19 crisis and in normal times. Moreover, the leadership challenges of addressing the socially structured health disparities may not have received the research attention they deserve. Healthcare organisations need leadership that can understand the complex biosocial realities that determines who falls ill and that embraces diversity in the planning and provision of services.

A second challenge is the need for healthcare organisations to better develop the leadership potential of all of their staff, ${ }^{7}$ regardless of race, gender, class or social background. This challenge likely stems from deeply rooted cultural biases. Our ideas of leaders and leadership are historically and culturally shaped. Even if 'the great man theory' is less relevant today, the portrayal of leaders often echoes the notions that people with certain characteristics-white men (who are usually also both tall and thin) in North America, the UK, Europe and Australia-are the ones who best fit the job. These social and cultural blind spots can lead people to underestimate the leadership potential of people who do not fit the stereotypes that inform cultural constructions of leaders and leadership. ${ }^{8}$ Even more insidious, people are often judged negatively or penalised for acting in ways that do not conform to socially and culturally defined gendered and racialised roles. For example, a woman can be judged negatively for speaking assertively or for putting herself forward for a promotion or raise, and black women even more so. As a result, a black or Asian female leader can be judged negatively for behaviours that are acceptable or even valued in a white male leader. $^{89}$

In response to these challenges, we will shine a light on diversity and inclusion and we will broaden and change ideas of leaders and leadership. Nurturing diverse talent, and allowing diverse leaders to act in ways that we hope and expect our leaders to act, then, is an enduring challenge. In a recent article in BMJ Leader, Gilmartin et al focus on diversity and gender balance among leaders as an important organisational capacity, and offer tangible advice on how this capacity can be developed. ${ }^{10}$ Gender diversity in leadership can be enhanced through the combination of mentorship, talent management, training and network opportunities, improvements to advertising, interview panel diversity and succession planning. ${ }^{8}$ Talent needs to be nurtured, and organisations need policies for inclusion and talent management that embraces and promotes diversity. Diversity in teams is associated with better results, recruitment and retention. Diversity in leadership can foster flexible and dynamic organisations that adopt to new challenges.

As an academic journal focused on disseminating knowledge about leaders and leadership in health and care, $B M J$ Leader also has its blind spots and challenges. We have a responsibility to publish research and open up other forms of dialogue that can help organisations and leaders better address the health effects of inequity. We also have a responsibility 
to publish research and open up dialogue that can help organisations develop the leadership potential of all staff. Though a relatively young journal, publishing now for just 3 years, we realise that we may not have prioritised these research topics as much we should have. However, we now see and recognise this blind spot, and are committed to action.

BMJ Leader responded quickly and, we hope, creatively to the COVID-19 pandemic, developing research, reflective essays, commentaries and interviews that aim to shed new insight into the challenges organisations face and the actions they might take in response to this novel global health crisis. We need to be equally quick and creative to respond to the longer standing inequities that have prevented health and care organisations from realising their full potential. We also need to highlight proactive leadership approaches to tackling disparities in health and clinical outcomes.

For this longstanding issue, however, we need a longer term approach. BMJ Leader aim to act to keep making our blind spots smaller. As an editorial team, we will to take stock of our progress in a year's time, and to learn from our successes and failures. We hope through our commitment now, and the expectation that we will continually evaluate and learn, that we will help translate the current public attention on race and racism into a more enduring commitment to publish research and initiate dialogue on how leaders can better address the challenges posed by all forms of inequity in the years to come.

We will welcome and consider readers' suggestions about how we, as an editorial team, and the BMJ Leader community more broadly can best go about this. You can write to us at info.bmjleader@bmj. com or tweet to@bmjleader.

Twitter Jan C Frich @J_Frich, Dominique Allwood @ DrDominiqueAllw, Anthony Robert Berendt @tony_ berendt, Pedro Delgado @pedrolHI, Rachel Dunscombe @ukpenguin, Bob Klaber @bobklaber, Aoife Caitlin Molloy@DrAoifeMolloy and James Mountford @ mountfordjames

Contributors All authors contributed to the drafting and editing of this editorial. Author ordering, except from the first author, is alphabetical.

Funding The authors have not declared a specific grant for this research from any funding agency in the public, commercial or not-for-profit sectors.

Competing interests None declared.

Patient consent for publication Not required.

Provenance and peer review Not commissioned; internally peer reviewed.

(C) Author(s) (or their employer(s)) 2021. No commercial re-use. See rights and permissions. Published by BMJ.

(A) Check for updates

To cite: Frich JC, Allwood D, Berendt AR, et al. BMJ Leader 2021:5:1-2.

Received 7 September 2020

Accepted 1 October 2020

Published Online First 17 December 2020
BMJ Leader 2021;5:1-2. doi:10.1136/leader-2020-000378

ORCID iDs

Jan C Frich http://orcid.org/0000-0001-9079-7508 Rachel Dunscombe http://orcid.org/0000-0002-22667063

Aoife Caitlin Molloy http://orcid.org/0000-0003-40586715

Amit Nigam http://orcid.org/0000-0002-6772-9643 Catherine Stoddart http://orcid.org/0000-0001-50775099

Tim Swanwick http://orcid.org/0000-0002-4185-0736

\section{REFERENCES}

1 Violence GJ, Galtung J. Violence, peace, and peace research. J Peace Res 1969:6:167-91.

2 Hall W. Social class and survival on the s.s. titanic. Soc Sci Med 1986;22:687-90.

3 World Health Organization. Closing the gap in a generation: health equity through action on the social determinants of health. final report of the Commission on social determinants of health, 2008.

4 Peek N, Sujan M, Scott P. Digital health and care in pandemic times: impact of COVID-19. BMJ Health Care Inform 2020;27:e100166.

5 Lloyd-Smith M. The COVID-19 pandemic: resilient organisational response to a low-chance, high-impact event. BMJ Leader 2020:4:109-12.

6 Farmer P. Infections and inequalities: the modern plagues. Berkeley, CA: University of Calilfornia Press, 1999.

7 Frich JC, Brewster AL, Cherlin EJ, et al. Leadership development programs for physicians: a systematic review. J Gen Intern Med 2015;30:656-74.

8 Eagly AH, Karau SJ. Role congruity theory of prejudice toward female leaders. Psychol Rev 2002;109:573-98.

9 Rosette AS, Koval CZ, Ma A, et al. Race matters for women leaders: intersectional effects on agentic deficiencies and penalties. Leadersh $Q$ 2016;27:429-45.

10 Gilmartin M, Woods N, Patel S, et al. Diversity in NHS clinical leadership: is better talent management the route to gender balance? BMJ Leader 2020;4:45-7. 